\title{
Investigation of the Consecutive Electron Transfer of Metalloporphyrin Species on the Simulative Cell Membrane by Thin Layer Cyclic Voltammetry
}

\author{
Wenting $G u^{1,2}$, Wenjian $\mathrm{Li}^{1,2}$, Ruiyuan Liu ${ }^{1}$ and Yin $Q u^{1}$, Libin Zhou ${ }^{1 *}$, Xicun Dong ${ }^{1, *}$ \\ ${ }^{1}$ Institute of Modern Physics, Chinese Academy of Sciences, Lanzhou 730000, China \\ ${ }^{2}$ School of Life Sciences, Lanzhou University, Lanzhou 730000, China \\ ${ }^{3}$ Key Laboratory of Bioelectrochemistry\&Environmental Analysis of Gansu Province, College of \\ Chemistry \& Chemical Engineering, Northwest Normal University, Lanzhou 730070, China \\ *E-mail: dongxicun@impcas.ac.cn, libinzhou@impcas.ac.cn
}

doi: $10.20964 / 110345$

Received: 7 January 2016 / Accepted: 2 March 2016 / Published: 1 April 2016

\begin{abstract}
Metalloporphyrin, which is the essential sites of electron transfer in biological system, can be investigated the electrochemical process on cell membrane. The liquid/liquid interface is suitable to simulate process of heterogeneous electron transfer between two immiscible electrolyte solutions by thin layer cyclic voltammetry conveniently. As the excellent electron receptors, metalloporphyrins obtained electrons from the electron donor $\mathrm{Fe}(\mathrm{CN})_{6}{ }^{4-}$, and the kinetics constants of multi-step interfacial bimolecular reaction were obtained simultaneously at the interface by thin-layer theory. Our experimental results suggested that the rate of electron transfer in the liquid/liquid interface depends on the presence of different metallic ions located the porphyrin ring. In addition, it is noted that the dependence of driving force on rate constants follows the well-known Bulter-Volmer equation. This electrochemical approach to quantitatively measure and analysis the dynamic process on cell membrane is a potential marker for the evaluation of electron transfer process in cell.
\end{abstract}

Keywords: Thin-layer cyclic voltammetry, Metalloporphyrin, Multi-step electron transfer, liquid/liquid interface

\section{$\underline{\text { FULL TEXT }}$}

(C) 2016 The Authors. Published by ESG (www.electrochemsci.org). This article is an open access article distributed under the terms and conditions of the Creative Commons Attribution license (http://creativecommons.org/licenses/by/4.0/). 